\title{
Article \\ Obesity and Uncontrolled Diabetes Predict Depression in HF Patients
}

\author{
Albenita Fetahu ${ }^{1}$, Kaltrinë Rrustemi ${ }^{1}$, Michael Y. Henein ${ }^{2,3,4}$ (D), Besim Bytyçi ${ }^{5}$, Flamure Mehmeti ${ }^{6}$, \\ Ibadete Bytyçi ${ }^{1,2,6}$ (D) and Lulzim Kamberi ${ }^{6, *}$
}

1 Department of Nursing, Universi College, 10000 Prishtina, Kosovo; albenita.fetahu1@gmail.com (A.F.); kaltrinna_rrustemi@hotmail.com (K.R.); i.bytyci@hotmail.com (I.B.)

2 Institute of Public Health and Clinical Medicine, Umea University, 90187 Umea, Sweden; michael.henein@umu.se

3 Molecular and Clinic Research Institute, St George University, London SW17 OQT, UK

4 Institute of Fluid Dynamics, Brunel University, London UB8 3PH, UK

5 Clinic of Rheumatology, University Clinical Centre of Kosovo, 10000 Prishtina, Kosovo; besim.bytyqi@hotmail.com

6 Clinic of Cardiology, University Clinical Centre of Kosovo, 10000 Prishtina, Kosovo; flamuremehmeti@gmail.com

* Correspondence: lulzimkamberi@gmail.com; Tel.: +383-49-145-680

Citation: Fetahu, A.; Rrustemi, K.; Henein, M.Y.; Bytyçi, B.; Mehmeti, F.; Bytyçi, I.; Kamberi, L. Obesity and Uncontrolled Diabetes Predict Depression in HF Patients. J. Clin. Med. 2021, 10, 5663. https://doi.org/ $10.3390 / \mathrm{jcm} 10235663$

Academic Editor: Christian Sohns

Received: 13 October 2021

Accepted: 23 November 2021

Published: 30 November 2021

Publisher's Note: MDPI stays neutral with regard to jurisdictional claims in published maps and institutional affiliations.

Copyright: (c) 2021 by the authors. Licensee MDPI, Basel, Switzerland. This article is an open access article distributed under the terms and conditions of the Creative Commons Attribution (CC BY) license (https:/ / creativecommons.org/licenses/by/ $4.0 /)$.

\begin{abstract}
Background and aim: Heart failure (HF) is a clinical syndrome associated with poor quality of life and prognosis, and premature mortality. The aim of this study was to assess the prevalence of depression and its risk factors in HF patients. Methods: The study included 151 HF patients (mean age of $66.6 \pm 11$ years, $52.3 \%$ female). Based on ejection fraction (EF), the study cohort was divided into the following two groups: group-I: HFpEF patients (EF $\geq 50 \%, n=47$ ) and group-II: HFrEF patients $(\mathrm{EF}<40 \%, n=104)$. For the enrolled patients, demographic, clinic and echocardiographic indices, and depression scale results were collected. Results: The patients with HF and depression were older, mostly females, more obese, and had a higher glycemic level and higher NYHA functional class compared with the patients without depression ( $p<0.05$ for all). The left ventricle (LV) and left atrial (LA) dimensions were larger, and EF was lower, in patients with depression compared to those without depression ( $p<0.05$ for all), while the right ventricle (RV) measurements did not differ $(p>0.05)$. The same parameters remained significantly different when the patients were divided into HFpEF and HFrEF. The depression scale correlated with glycemic level ( $\mathrm{r}=0.51, p=0.01)$, obesity $(\mathrm{rpb}=0.53, p=0.001)$, age $(\mathrm{r}=0.47, p=0.02)$, and severity of NYHA class ( $\mathrm{rpb}=0.54, p=0.001)$. On a multivariate model, $\mathrm{BMI} \geq 30 \mathrm{~kg} / \mathrm{m}^{2}$, OR 1.890 (1.199 to $\left.3.551 ; 0.02\right)$ glycemic level $\geq 8.5 \mathrm{mmol} / \mathrm{L}$, OR 2.802 (1.709 to 5.077; $p=0.01$ ), and NYHA class > 2, OR 2.103 (1.389 to 4.700; $p=0.01$ ), proved to be the most powerful independent predictors of depression, in the group as a whole. Obesity and uncontrolled diabetes predicted depression, irrespective of EF. Conclusions: In this modest cohort of HF patients, obesity and uncontrolled diabetes were independent predictors of depression, irrespective of LV systolic function. This emphasizes the important role of medical education for better control of such risk factors.
\end{abstract}

Keywords: heart failure; HFpEF; HFrEF; depression scale

\section{Introduction}

Heart failure (HF) is a known clinical syndrome and constitutes a major public health problem associated with poor quality of life and prognosis, and premature mortality [1]. It is well established that depression is an independent risk factor for HF due to coronary artery disease and other cardiac diseases [2], and symptoms of depression are also associated with a greater risk of adverse cardiac events [3]. It has been suggested that HF itself could have a causal relationship with the onset of depression, since some parts of the brain are especially vulnerable to suboptimal perfusion, especially with reduced cardiac output and underlying 
cerebral atherosclerosis [4]. The classical hypothesis supports a link between the onset of depression and suffering from chronic stress in patients with chronic heart disease [5]. In addition, depression itself reduces the quality of life, not only in isolated psychiatric disorders, as a primary condition, but also in other concomitant diseases. Despite the fact that depression should be approached within a care program in patients with HF, it is not always considered a serious issue, and clinicians may only focus on the heart problem, thus underestimating the clinical impact of depression [6,7].

The aim of this study was to assess the prevalence of depression among HF patients and to identify the risk factors predicting it.

\section{Methods}

\subsection{Study Population}

We studied 151 consecutive patients with clinical signs and symptoms of HF with New York Heart Association (NYHA) functional class I-IV, according to the current ESC guidelines [8]. Based on left ventricular ejection fraction $(\mathrm{EF})$, patients were divided into HF with reduced $\mathrm{EF}(\mathrm{EF}<40 \%, \mathrm{HFrEF}, n=104)$ and $\mathrm{HF}$ with preserved $\mathrm{EF}(\mathrm{EF} \geq 50 \%$, $\mathrm{HFpEF}$, $n=47$; Figure S1). All patients were referred to the Clinic of Cardiology, University Clinical Center of Kosovo, Prishtina, Kosovo between June and October 2019. Exclusion criteria were as follows: history of congenital heart disease, pacemaker implantation, valvular surgery, cardiac transplantation, chronic obstructive pulmonary disease (COPD) or recent acute coronary syndrome, stroke, age $<18$ years and patients with psychiatric disorders diagnosed before heart failure. The study was approved by the local institutional review board and all patients gave written informed consent before enrollment in the study.

\subsection{Data Collection}

Detailed history, clinical, ECG and echocardiographic assessments were obtained in all patients. Cardiac risk factors, such as diabetes mellitus (DM), arterial hypertension $(\mathrm{AH})$, dyslipidemia, coronary heart disease (CHD), and smoking, were assessed. The routine biochemical test results were collected, including complete blood count, blood glucose, cholesterol, triglyceride, albumin, protein, kidney and liver function as well as weight and height measurements. According to the World Health Organization conventional international risk factor assessment and cut-off values for body mass index (BMI), underweight was defined as BMI $<18.5 \mathrm{~kg} / \mathrm{m}^{2}$, normal weight was BMI $18.5-24.9 \mathrm{~kg} / \mathrm{m}^{2}$, overweight was defined as BMI of $25-29.9 \mathrm{~kg} / \mathrm{m}^{2}$, and obesity as BMI $\geq 30 \mathrm{~kg} / \mathrm{m}^{2}$ [9]. Echocardiographic indices, such as left ventricle end diastolic dimension (LVEDD), LV systolic dimension (LVESD), LV ejection fraction (LVEF), and left atrial (LA), right atrial (RA) and right ventricle (RV) dimensions, were also collected.

\subsection{Depression Assessment}

Depression was assessed using Patient Health Questionnaire-9 (PHQ-9), an instrument for screening, diagnosing, monitoring and measuring the severity of depression. PHQ-9 score obtained by adding score for each question with score that ranged 0-27. Total scores of $5,10,15$, and 20 represent cut-off points for mild, moderate, moderately severe and severe depression, respectively. A score of PHQ-9 $\geq 10$ was used to define the presence of moderate depression [10].

\subsection{Statistical Analysis}

Statistical analysis was performed using SPSS Software Package version 26.0 (IBM Corp., Armonk, NY, USA). Data are summarized using frequencies (percentages) for categorical variables and mean \pm standard deviation (SD) for continuous variables or median interquartile (IRQ) ranges. Continuous data were compared with two-tailed Student $t$ test and discrete data with chi-square test. The degrees of association between clinical, biochemical and depression scales were determined using the Pearson's correlation coefficient, in the case of continuous variables, chi-square test (categorical variables) and 
point biserial correlation in the case of categorical and continuous variables. A significant difference was defined as $p$ value $<0.05$ (2-tailed).

\section{Results}

\subsection{Demographic and Clinical Data of HF Patients}

One hundred and fifty-one patients were included in the study, with a mean LVEF of $47 \pm 7.8 \%$ and NYHA functional class of $2.3 \pm 1.0$. The patients' mean age was $66.6 \pm$ 11 years, and $52.3 \%$ were females and $19.2 \%$ were current smokers. Further, $28.5 \%$ of the patients were obese, $66.2 \%$ were hypertensives $(\mathrm{AH}), 48.4 \%$ were diabetics $(\mathrm{DM}), 43.8 \%$ had coronary heart disease (CHD), and $47.1 \%$ had atrial fibrillation (AF). Additionally, $78.2 \%$ of the patients were receiving aspirin, $82.8 \% \mathrm{ACE} / \mathrm{ARBs}, 70.9 \%$ diuretics, $73.5 \%$ beta blockers, $15.2 \%$ calcium channels blockers, and $17.9 \%$ were undergoing anticoagulation therapy (Table S1). The biochemical and echocardiographic data are presented in Tables S2 and S3.

\subsection{Demographic and Clinical Data of the Patients with and without Depression}

Out of the 151 studied patients, $33(19.8 \%)$ had a total score $>10$ or were diagnosed with moderate depression. The patients with HF and depression were older $(p=0.01)$, mostly females $(p=0.02)$, more obese $(p=0.02)$, and had a higher NYHA functional class $(p=0.01)$ compared to those without depression. AF and DM were more prevalent among HF patients with depression ( $p<0.05$ for both), while AH, dyslipidemia, and CHD were not significantly different between the groups ( $p>0.05$ for all). Similarly, the HF patients with depression were receiving more anticoagulants and diuretics ( $p<0.05$ for both) compared to those without depression, but the other medications were not different between the groups ( $p>0.05$ for all; Table S1).

\subsection{Biochemical and Echocardiographic Indices of Patients with and without Depression}

The HF patients with depression had a higher glycemic level, higher markers of kidney dysfunction, and lower iron levels ( $p<0.05$ for all) compared to those without depression. The other biochemical indices did not differ between the groups $(p>0.05$ for all; Table S2). Additionally, the HF patients with depression had larger LVEDD $(p=0.03)$, larger LVESD $(p=0.02)$, lower LVEF $(p=0.01)$, and a larger LA dimension $(p=0.03)$ compared to those without depression. The RA and RV measurements did not differ between the two patient groups (Table S3).

\subsection{Demographic and Clinical Data of Patients according to EF}

The HFrEF patients with depression were predominantly female $(p=0.03)$ and had a higher NYHA functional class $(p=0.02)$ compared to those without depression. $\mathrm{DM}$, obesity, and AF were more prevalent among the HFrEF patients with depression ( $p<0.05$ for all), while AH, dyslipidemia, and CHD were not different from those without depression $(p>0.05)$. Although the HFrEF patients with depression were receiving more diuretics and anticoagulants, the other medications were not different from those without depression. Among the HFpEF patients, the depression group were older compared to those without depression $(p=0.02)$. Similarly to the HFrEF group, the frequency of females, obesity, DM, and AF were higher in the HFpEF patients with depression compared to those without depression. In contrast, the frequency of patients receiving anticoagulation medications was higher, and antiarrhythmic drugs tended to be more prevalent among the group with depression compared to the group without depression (Table 1). 
Table 1. Demographic and clinical data between HF patients with and without depression according to EF.

\begin{tabular}{|c|c|c|c|c|c|c|}
\hline Variable & $\begin{array}{l}\text { HFrEF without } \\
\text { Depression } \\
(n=81)\end{array}$ & $\begin{array}{l}\text { HFrEF with } \\
\text { Depression } \\
\quad(n=23)\end{array}$ & $p$ Value & $\begin{array}{l}\text { HFpEF without } \\
\text { Depression } \\
(n=37)\end{array}$ & $\begin{array}{l}\text { HFpEF with } \\
\text { Depression } \\
\quad(n=10)\end{array}$ & $p$ Value \\
\hline \multicolumn{7}{|l|}{ Clinical indices } \\
\hline Age & $71.1 \pm 11$ & $68.2 \pm 10$ & 0.12 & $60.1 \pm 12$ & $68.2 \pm 11$ & 0.04 \\
\hline Sex (female, \%) & $41(50.6)$ & $14(60.8)$ & 0.03 & $18(48.6)$ & $6(60)$ & 0.01 \\
\hline Smoking $(n, \%)$ & $21(25.9)$ & $5(21.7)$ & 0.12 & $8(21.6)$ & $2(20)$ & 0.33 \\
\hline $\operatorname{BMI}\left(\mathrm{m} / \mathrm{kg}^{2}\right)$ & $26.3 \pm 3.5$ & $30.4 \pm 2.9$ & 0.04 & $27.9 \pm 3.3$ & $28.8 \pm 4.4$ & 0.13 \\
\hline Underweight $(n, \%)$ & $1(1.23)$ & $0(0)$ & 0.04 & $0(0)$ & $0(0)$ & 0.77 \\
\hline Normal weight $(n, \%)$ & $29(35.8)$ & $11(47.8)$ & 0.03 & $13(43.2)$ & $4(40)$ & 0.31 \\
\hline Overweight $(n, \%)$ & $29(35.8)$ & $10(43.5)$ & 0.04 & $15(40.5)$ & $5(50)$ & 0.003 \\
\hline Obese $(n, \%)$ & $21(25.9)$ & $8(34.7)$ & 0.02 & $10(27.0)$ & $4(40)$ & 0.002 \\
\hline $\mathrm{SBP}(\mathrm{mmHg})$ & $106 \pm 15$ & $108 \pm 14$ & 0.63 & $111 \pm 16$ & $109 \pm 14$ & 0.70 \\
\hline DBP (mmHg) & $78.1 \pm 10$ & $75 \pm 13$ & 0.32 & $83 \pm 12$ & $78 \pm 16$ & 0.52 \\
\hline HR (beats/min) & $75 \pm 10$ & $73 \pm 11$ & 0.31 & $76 \pm 13$ & $74 \pm 10$ & 0.41 \\
\hline NYHA class & $1.8 \pm 1.0$ & $2.9 \pm 1.1$ & 0.02 & $1.8 \pm 0.9$ & $2.9 \pm 1.1$ & 0.03 \\
\hline \multicolumn{7}{|l|}{ Comorbidities } \\
\hline $\mathrm{AH}(n, \%)$ & $56(69.1)$ & $14(60.9)$ & 0.08 & $24(64.8)$ & $6(60)$ & 0.10 \\
\hline $\mathrm{DM}(n, \%)$ & $39(48.1)$ & $13(56.5)$ & 0.04 & $16(43.1)$ & $5(50)$ & 0.03 \\
\hline Dyslipidemia & $23(28.4)$ & $7(30.4)$ & 0.51 & $10(27.0)$ & $3(30)$ & 0.61 \\
\hline $\operatorname{CHD}(n, \%)$ & $41(50.6)$ & $12(52.2)$ & 0.21 & $14(37.8)$ & $4(40)$ & 0.33 \\
\hline $\operatorname{AF}(n, \%)$ & $40(51.8)$ & $15(65.2)$ & 0.01 & $12(32.4)$ & $4(40)$ & 0.03 \\
\hline \multicolumn{7}{|l|}{ Drugs } \\
\hline Aspirin $(n, \%)$ & $64(79.1)$ & $18(78.2)$ & 0.27 & $28(75.7)$ & $8(80)$ & 0.47 \\
\hline $\operatorname{ACE} / \operatorname{ARBs}(n, \%)$ & $67(82.7)$ & $19(82.6)$ & 0.55 & $30(81.1)$ & $8(80)$ & 0.35 \\
\hline Diuretics $(n, \%)$ & $58(71.6)$ & $20(86.9)$ & 0.001 & $22(59.5)$ & $7(70)$ & 0.02 \\
\hline $\mathrm{BB}(n, \%)$ & $64(79.1)$ & $19(78.2)$ & 0.20 & $26(70.3)$ & $7(70)$ & 0.80 \\
\hline $\operatorname{CCB}(n, \%)$ & $11(13.6)$ & $3(13.1)$ & 0.51 & $7(18.9)$ & $2(20)$ & 0.33 \\
\hline Antiarrhythmic $(n, \%)$ & $14(17.3)$ & $5(21.7)$ & 0.21 & $6(16.2)$ & $2(20)$ & 0.09 \\
\hline Anticoagulation $(n, \%)$ & $15(18.5)$ & $7(30.4)$ & 0.01 & $4(10.8)$ & $1(10)$ & 0.21 \\
\hline Statins $(n, \%)$ & $29(29.6)$ & $7(30.4)$ & 0.41 & $6(16.2)$ & $1(10)$ & 0.11 \\
\hline
\end{tabular}

Body mass index (BMI), New York Heart Association (NYHA), arterial hypertension (AH), diabetes mellitus (DM), dyslipidemia, coronary heart disease (CHD), atrial fibrillation (AF); Systolic blood pressure (SBP), diastolic blood pressure (DBP), heart rate (HR), angiotensin converting enzyme (ACE), angiotensin II receptors blockers (ARBs), beta clockers (BB), channel calcium blockers (CCB).

\subsection{Biochemical and Echocardiographic Indices of Patients according to EF}

In the HFrEF patients, the glycemic level and markers of kidney dysfunction were higher, and the iron level was lower in patients with depression compared to those without depression $(p<0.05$ for all), but the other biochemical indices were not different $(p>0.05)$. The echocardiographic indices, including the LV systolic and diastolic dimensions and EF, as well as the LA, RA, and RV dimensions, did not differ between the groups ( $p>0.05$ for all). Almost similar results were shown in the HFpEF groups ( $p>0.05$ for all; Tables 2 and 3).

Table 2. Laboratory data between HF patients with and without depression according to EF.

\begin{tabular}{|c|c|c|c|c|c|c|}
\hline Variable & $\begin{array}{l}\text { HFrEF without } \\
\text { Depression } \\
(n=81)\end{array}$ & $\begin{array}{l}\text { HFrEF with } \\
\text { Depression } \\
\quad(n=23)\end{array}$ & $p$ Value & $\begin{array}{c}\text { HFpEF } \\
\text { without } \\
\text { Depression } \\
(n=37)\end{array}$ & $\begin{array}{l}\text { HFpEF with } \\
\text { Depression } \\
\quad(n=10)\end{array}$ & $p$ Value \\
\hline \multicolumn{7}{|l|}{ Laboratory data } \\
\hline Glucose (mmol/L) & $5.9 \pm 2.2$ & $5.6 \pm 1.2$ & 0.02 & $5.6 \pm 1.2$ & $8.2 \pm 3.2$ & 0.02 \\
\hline Urea $(\mathrm{mmol} / \mathrm{L})$ & $9.4 \pm 5.6$ & $16.1 \pm 6.2$ & 0.03 & $8.3 \pm 4.2$ & $14 \pm 5.1$ & 0.04 \\
\hline Creatinine (umol/L) & $125 \pm 11$ & $165 \pm 25$ & 0.01 & $123 \pm 11$ & $145 \pm 19$ & 0.02 \\
\hline Bilirubin (mg/dL) & $4.1 \pm 1.1$ & $5.5 \pm 1.1$ & 0.21 & $3.8 \pm 1.3$ & $4.9 \pm 1.3$ & 0.33 \\
\hline $\operatorname{ALT}(\mathrm{U} / \mathrm{L})$ & $30 \pm 10$ & $37 \pm 11$ & 0.32 & $34 \pm 11$ & $30 \pm 10$ & 0.18 \\
\hline AST (U/L) & $33 \pm 13$ & $28 \pm 10$ & 0.51 & $30 \pm 10$ & $28 \pm 14$ & 0.31 \\
\hline Albumin (g/L) & $30.3 \pm 8.5$ & $33 \pm 9.1$ & 0.24 & $31 \pm 10$ & $33 \pm 9.6$ & 0.32 \\
\hline Protein $(\mathrm{g} / \mathrm{L})$ & $59 \pm 11$ & $61 \pm 10$ & 0.24 & $62 \pm 10$ & $64 \pm 11$ & 0.28 \\
\hline Cholesterol (mmol/L) & $6.8 \pm 3.2$ & $6.2 \pm 3.1$ & 0.22 & $5.9 \pm 3.5$ & $6.8 \pm 3.1$ & 0.38 \\
\hline Triglyceride (mmol/L) & $1.9 \pm 0.8$ & $2.1 \pm 0.9$ & 0.31 & $1.9 \pm 0.8$ & $2.2 \pm 0.7$ & 0.22 \\
\hline $\operatorname{WBC}\left(10^{3} / \mathrm{mm}^{3}\right)$ & $9.4 \pm 4.3$ & $8.2 \pm 4.6$ & 0.29 & $9.2 \pm 4.6$ & $8.9 \pm 3.4$ & 0.37 \\
\hline $\operatorname{RBC}\left(10^{6} / \mathrm{mm}^{3}\right)$ & $3.9 \pm 1.2$ & $4.4 \pm 1.2$ & 0.23 & $4.1 \pm 1.2$ & $4.7 \pm 1.1$ & 0.38 \\
\hline Platelet $\left(10^{3} / \mathrm{mm}^{3}\right.$ & $212 \pm 23$ & $217 \pm 22$ & 0.21 & $209 \pm 21$ & $215 \pm 25$ & 0.11 \\
\hline Iron (umol/L) & $8.8 \pm 2.8$ & $13.1 \pm 3.1$ & 0.03 & $10.2 \pm 3.1$ & $9.9 \pm 2.5$ & 0.20 \\
\hline
\end{tabular}


Table 3. Echocardiographic data between HF patients with and without depression according to EF.

\begin{tabular}{cccccc}
\hline Variable & $\begin{array}{c}\text { HFrEF without } \\
\text { Depression } \\
(\boldsymbol{n}=\mathbf{8 1 )}\end{array}$ & $\begin{array}{c}\text { HFrEF with } \\
\text { Depression } \\
(\boldsymbol{n}=\mathbf{2 3})\end{array}$ & $\boldsymbol{p}$ Value & $\begin{array}{c}\text { HFpEF } \\
\text { without } \\
\text { Depression } \\
(\boldsymbol{n}=\mathbf{3 7 )}\end{array}$ & $\begin{array}{c}\text { HFpEF with } \\
\text { Depression } \\
(\boldsymbol{n}=\mathbf{1 0})\end{array}$ \\
\hline LV EDD $(\mathrm{cm})$ & $5.7 \pm 0.6$ & $6.1 \pm 0.7$ & 0.10 & $5.1 \pm 0.4$ & $5.3 \pm 0.6$ \\
LV ESD (cm) & $3.5 \pm 0.4$ & $3.9 \pm 0.4$ & 0.21 & $3.6 \pm 0.4$ & $3.8 \pm 0.5$ \\
IVSd (cm) & $1.1 \pm 0.1$ & $1.0 \pm 0.1$ & 0.30 & $1.1 \pm 0.1$ & $1.2 \pm 0.2$ \\
LVPWd (cm) & $1.1 \pm 0.2$ & $1.1 \pm 0.2$ & 0.18 & $1.0 \pm 0.1$ & $1.1 \pm 0.2$ \\
LV EF (\%) & $36 \pm 2.8$ & $34 \pm 3.5$ & 0.44 & $53 \pm 2.9$ & $55 \pm 4.3$ \\
LA diameter (cm) & $4.4 \pm 4.4$ & $4.6 \pm 4.2$ & 0.10 & $4.1 \pm 3.9$ & $4.2 \pm 5.6$ \\
RA diameter (cm) & $3.7 \pm 1.4$ & $3.8 \pm 1.5$ & 0.23 & $3.4 \pm 1.6$ & $3.5 \pm 1.3$ \\
RV diameter $(\mathrm{cm})$ & $3.3 \pm 1.2$ & $3.5 \pm 1.2$ & 0.55 & $3.1 \pm 1.1$ & $3.2 \pm 1.3$ \\
\hline
\end{tabular}

LV: left ventricle; EDD: end-diastolic dimension; ESD: end-systolic dimension; IVSd: inter-ventricular septum in diastole; PWd: parietal wall in diastole; EF: ejection fraction; LA: left atrium; RA: right atrium; RV: right ventricle.

\subsection{Correlation between Cardiovascular Risk Factors and Depression}

The depression scale correlated with the glycemic level $(\mathrm{r}=0.51, p=0.01)$, BMI $(\mathrm{r}=$ $0.52, p=0.01)$, severity of NYHA class $\left(\mathrm{r}_{\mathrm{pb}}=0.54, p=0.001\right)$, and only modestly with age $(\mathrm{r}=0.43, p=0.02$; Figure 1). In contrast, no relationship was found between depression and $\mathrm{AH}(\mathrm{r}=22, p=0.11)$ or dyslipidemia $(\mathrm{r}=0.17, p=0.31)$, but AF tended to have a relationship with depression $\left(\mathrm{r}_{\mathrm{pb}}=0.21, p=0.08\right)$.
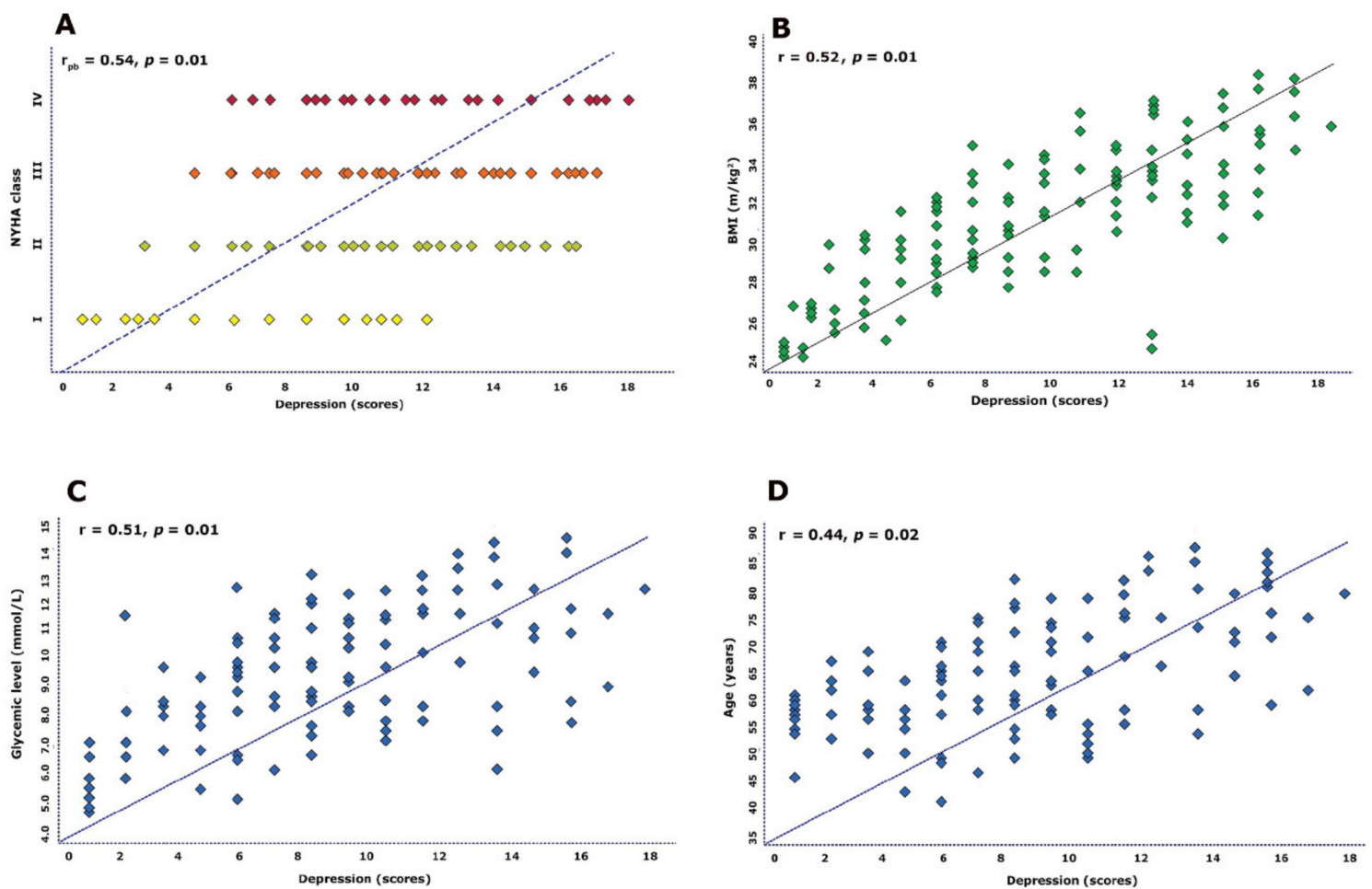

Figure 1. Correlation of demographic and clinical indices with depression; (A) correlation between New York Heart Association class (NYHA) class and depression; (B) correlation between Body mass index (BMI) and depression; (C) correlation between glycemic level and depression; (D) correlation between age and depression. 


\subsection{Predictors of Depression in the Studied Cohort}

The prevalence of depression in the study participants was $21.8 \%$, with no difference between HFrEF and HFpEF ( $22.1 \%$ vs. $21.2 \%$, respectively; $p=n s$ ). In the univariate analysis, age $(p=0.03)$, female gender $(p=0.04)$, NYHA class $>$ II $(p=0.01)$, BMI $\geq$ $30 \mathrm{~kg} / \mathrm{m}^{2}(p=0.01)$, and glycemic level $\geq 8.5 \mathrm{mmol} / \mathrm{L}(p=0.001)$ predicted moderate depression. In the multivariate model, $\mathrm{BMI} \geq 30 \mathrm{~kg} / \mathrm{m}^{2}$, OR 1.890 [(1.199 to 3.551) 0.02], glycemic level $\geq 8.5 \mathrm{mmol} / \mathrm{L}$, OR 2.802 [(1.709 to 5.077), $p=0.01$ ], and NYHA class $>2$, OR 2.103 [(1.389 to 4.700$) p=0.01$ ], proved to be the most powerful independent predictors of depression in the HF cohort (Table 4) as a whole. Testing different factors that predict depression, based on LV EF, showed that NYHA class >II (OR 2.091; $p=0.01$ ), obesity (OR $1.911 ; p=0.03)$, and uncontrolled DM (OR 2.013; $p=0.01)$ were independent predictors of depression in HFrEF patients, while female gender (OR 1.591; $p=0.04$ ), obesity (OR 1.926; $p=0.02$ ), and uncontrolled diabetes (OR 1.703; $p=0.03$ ) were independent predictors of depression in the HFpEF group (Table 4). Collinearity between these measurements was not met based on VIF $<10$ for all the predictors.

Table 4. Predictors of depression in HF patients.

\begin{tabular}{|c|c|c|c|c|}
\hline Variable & $\begin{array}{c}\text { Univariate Predictors } \\
\text { OR }(95 \% \mathrm{CI})\end{array}$ & $p$ Value & $\begin{array}{l}\text { Multivariate } \\
\text { Predictors } \\
\text { OR }(95 \% \text { CI) }\end{array}$ & $p$ Value \\
\hline \multicolumn{5}{|c|}{ HF patients } \\
\hline Age & $1.231(1.051$ to 2.401$)$ & 0.03 & $1.362(0.989$ to 3.824$)$ & 0.10 \\
\hline Female gender & $2.735(1.337$ to 5.595$)$ & 0.04 & $1.562(0.809$ to 4.024$)$ & 0.22 \\
\hline NYHA class $>$ II & $2.035(1.437$ to 4.595$)$ & 0.01 & $2.103(1.389$ to 4.700$)$ & 0.01 \\
\hline $\mathrm{AH}$ & $1.018(0.509$ to 3.903$)$ & 0.61 & & \\
\hline CHD & $1.141(0.819$ to 3.898$)$ & 0.11 & & \\
\hline BMI & 1.201 (0.909 to 4.108$)$ & 0.10 & & \\
\hline $\mathrm{BMI} \geq 30 \mathrm{~kg} / \mathrm{m}^{2}$ & $1.630(1.207$ to 3.803$)$ & 0.01 & $1.890(1.199$ to 3.551$)$ & 0.02 \\
\hline Diabetes & $1.105(0.895$ to 3.796$)$ & 0.09 & & \\
\hline Glycemic level $\geq 8.5 \mathrm{mmol} / \mathrm{L}$ & 2.105 (1.405 to 3.796$)$ & 0.001 & $2.802(1.709$ to 5.077$)$ & 0.01 \\
\hline \multicolumn{5}{|c|}{$\overline{\mathbf{H}} \overline{\mathrm{FrEF}} \overline{-}-\cdots$} \\
\hline Age & $1.191(1.091$ to 3.001$)$ & 0.04 & 1.701 (0.913 to 3.119$)$ & 0.11 \\
\hline Female gender & 1.135 (0.937 to 2.095$)$ & 0.10 & & \\
\hline NYHA class > II & $1.830(1.237$ to 3.005$)$ & 0.007 & 2.091 (1.613 to 4.009$)$ & 0.01 \\
\hline $\mathrm{AH}$ & $1.098(0.811$ to 3.211$)$ & 0.22 & & \\
\hline CHD & $1.109(0.709$ to 2.898$)$ & 0.31 & & \\
\hline BMI & $1.009(0.801$ to 3.701$)$ & 0.18 & & \\
\hline $\mathrm{BMI} \geq 30 \mathrm{~kg} / \mathrm{m}^{2}$ & $1.890(1.331$ to 3.908$)$ & 0.01 & $1.911(1.401$ to 4.018$)$ & 0.03 \\
\hline Diabetes & $1.205(0.801$ to 3.406$)$ & 0.21 & & \\
\hline Glycemic level $\geq 8.5 \mathrm{mmol} / \mathrm{L}$ & $1.961(1.519$ to 3.676$)$ & 0.02 & $2.013(1.519$ to 4.101$)$ & 0.01 \\
\hline \multicolumn{5}{|c|}{$\overline{\mathbf{H}} \overline{\mathbf{p}} \overline{\mathbf{E}} \overline{\mathbf{F}}$} \\
\hline Age & $1.161(1.007$ to 1.399$)$ & 0.02 & $1.301(0.977$ to 3.019$)$ & 0.08 \\
\hline Female gender & $1.511(1.193$ to 3.121$)$ & 0.04 & $1.591(1.110$ to 3.029$)$ & 0.04 \\
\hline NYHA class > II & $1.311(1.107$ to 2.901$)$ & 0.08 & & \\
\hline $\mathrm{AH}$ & $1.011(0.307$ to 2.101$)$ & 0.22 & & \\
\hline $\mathrm{CHD}$ & $1.122(0.530$ to 2.537$)$ & 0.61 & & \\
\hline BMI & $1.129(0.817$ to 3.160$)$ & 0.11 & & \\
\hline $\mathrm{BMI} \geq 30 \mathrm{~kg} / \mathrm{m}^{2}$ & $2.047(1.108$ to 3.397$)$ & 0.02 & $1.926(1.502$ to 4.011$)$ & 0.02 \\
\hline Diabetes & 1.118 (0.909 to 2.915$)$ & 0.17 & & \\
\hline Glycemic level $\geq 8.5 \mathrm{mmol} / \mathrm{L}$ & $1.808(1.015$ to 3.541$)$ & 0.03 & $1.703(1.311$ to 3101$)$ & 0.03 \\
\hline
\end{tabular}




\section{Discussion \\ 4.1. Findings}

Almost $22 \%$ of our studied patients with HF had moderate depression, irrespective of left ventricular EF. Moderate signs and symptoms of HF, based on NYHA, obesity, and uncontrolled diabetes, predicted the occurrence of depression in the group of patients as a whole. Obesity, uncontrolled diabetes, and NYHA class were independent predictors of depression in the HFrEF patients, while female gender, obesity, and uncontrolled diabetes were the respective predictors in the HFpEF group.

\subsection{Data Interpretation}

The overall prevalence rate of depression in our modest cohort of HF patients was $21.8 \%$, suggesting a clinical problem of similar impact to that previously reported in CHD patients [11,12]. Moderate depression was found in at least $20 \%$ of the patients, and such evidence cannot be clinically ignored, since it supports former reports that showed a relationship between HF and depression [13-15]. In this study, we also compared the prevalence of depression accordingly to left ventricular EF, in HFrEF and HFpEF patients. A moderate NYHA class, uncontrolled diabetes, and obesity were the main independent predictors of depression in the HF cohort as a whole. This finding is supported by previous reports, which showed a significant correlation between NYHA class and depression, with the prevalence of depression increasing with a higher NYHA functional class [16-18]. When splitting the patients' cohort, according to LV EF, into reduced (HFrEF) and preserved (HFpEF), our analysis showed some similarities and some differences in the risk factors predicting depression. Uncontrolled diabetes and obesity predicted the depression scale, irrespectively of EF. Again, this finding supports previous reports that showed patients with type 2 diabetes being at high risk for cardiovascular disease, heart failure, and depression [19]. Recognition of this common finding should have significant clinical implications, with optimum management of depression resulting in improved glycemic control [20]. Another related risk factor that we identified to predict depression, irrespective of LVEF, was obesity. This finding is supported by a large population study that showed obesity as an important factor associated with depression and HF [21]. It is well known that obesity, metabolic syndrome, and diabetes are three stages of the same disturbed pathophysiology. Our findings that showed uncontrolled diabetes and obesity as independent predictors of depression are then expected in a cohort of HF patients. Differences between the groups, according to LV EF, were of some interest. Female gender was proved to be an independent predictor of depression in HFpEF, but not in HFrEF. This finding can be explained by the higher frequency of female patients with $\mathrm{HFpEF}$ compared to HFrEF, which is expected based on the morphological presentation of the disease [22]. The stronger predictive value of the NYHA class of depression in HFrEF, but not HFpEF, could be explained by the higher incidence of CAD in the former compared with the latter $[14,23]$.

\subsection{Clinical Implications}

Clinicians need to focus more on the management of obesity, uncontrolled diabetes, and depressive symptoms in HF patients. Nonetheless, the findings of this study provide important information about some modifiable risk factors, including obesity and uncontrolled diabetes, that contribute to the occurrence of depression. If these factors are ignored, they can only lead to worsening of the overall clinical condition and quality of life of HF patients.

\subsection{Limitations}

This study has some limitations. The relatively small number of participants reflects the difficult nature of the study, design, and data collection. Defining depression on the basis of symptom severity, depending on questionnaires rather than a diagnostic interview, could be inadequate in some cases. The exact duration of the risk factors was not available, 
hence their accurate impact could be somewhat limited. In addition, the assessment of natriuretic peptides could have also helped to better predict the prognosis and severity of the disease, but this facility was not available.

\section{Conclusions}

In this modest cohort of HF patients, obesity, uncontrolled diabetes, and severity of NYHA functional class were independent predictors of depression. This emphasizes that the symptoms of depression should be considered in HF patients, and routine screening for depression and anxiety should be of crucial importance in high-risk patients.

Supplementary Materials: The following are available online at https: / www.mdpi.com/article/ 10.3390/jcm10235663/s1: Figure S1: flow chart of participants; Table S1: demographic and clinical data between HF patients with and without depression; Table S2: laboratory data between HF patients with and without depression; Table S3: echocardiographic data between HF patients with and without depression.

Author Contributions: L.K. and I.B.: Conceptualization, study design, methodology and project administration; A.F., K.R., F.M. and B.B.: data analysis and writing the first draft of manuscript. M.Y.H., L.K. and I.B. critically revised the draft. All authors have read and agreed to the published version of the manuscript.

Funding: This research received no external funding.

Institutional Review Board Statement: The study was conducted according to the guidelines of the Declaration of Helsinki and approved by the Local Institutional Board of Kosovo (No: 4585519).

Informed Consent Statement: Informed consent was obtained from all subjects involved the study.

Data Availability Statement: Not applicable.

Conflicts of Interest: The authors declare no conflict of interest.

\section{References}

1. Bytyçi, I.; Bajraktari, G. Mortality in heart failure patients. Anadolu Kardiyol. Derg. 2015, 15, 63-68. [CrossRef] [PubMed]

2. Alves, T.C.; Rays, J.; Fraguas, R., Jr.; Wajngarten, M.; Telles, R.M.; Duran, F.L.; Meneghetti, J.C.; Robilotta, C.C.; Prando, S.; De Castro, C.C.; et al. Association between major depressive symptoms in heat failure and impaired regional cerebral blood flow in the medial temporal region: A study using 99tc-HMPAO single photon emission computerized tomography (SPECT). Psychol. Med. 2006, 36, 597-608. [CrossRef] [PubMed]

3. Szyguła-Jurkiewicz, B.; Zakliczyński, M.; Ploch, M.; Mościński, M.; Partyka, R.; Wojnicz, R.; Zembala, M.; Polonski, L. Depression is the strongest predictor of long-term outcome in patients with chronic nonischemic heart failure. Pol. J. Cardio-Thorac. Surg. 2014, 11, 102-108. [CrossRef] [PubMed]

4. Rigas, A.; Farmakis, D.; Papingiotis, G.; Bakosis, G.; Parissis, J. Hypothalamic dysfunction in heart failure: Pathogenetic mechanisms and therapeutic implications. Fail. Rev. 2018, 23, 55-61. [CrossRef] [PubMed]

5. Thomas, S.A.; Chapa, D.W.; Friedmann, E.; Durden, C.; Ross, A.; Lee, M.C.; Lee, H.J. Depression in patients with heart failure: Prevalence, pathophysiological mechanisms, and treatment. Crit. Care Nurse 2008, 28, 40-55. [CrossRef] [PubMed]

6. Norra, C.; Skobel, E.C.; Arndt, M.; Schauerte, P. High impact of depression in heart failure: Early diagnosis and treatment options. Int. J. Cardiol. 2008, 125, 220-231. [CrossRef]

7. Pintor, L. Heart failure and depression, an often-neglected combination. Rev. Esp. Cardiol. 2006, 59, 761-765. [CrossRef]

8. Lang, R.M.; Badano, L.P.; Mor-Avi, V.; Afilalo, J.; Armstrong, A.; Ernande, L.; Flachskampf, F.A.; Foster, E.; Goldstein, S.A.; Kuznetsova, T.; et al. Recommendations for cardiac chamber quantification by echocardiography in adults: An update from the American Society of Echocardiography and the European Association of Cardiovascular Imaging. J. Am. Soc. Echocardiogr. 2015, 28, 1-39. [CrossRef] [PubMed]

9. Ponikowski, P.; Voors, A.A.; Anker, S.D.; Bueno, H.; Cleland, J.G.F.; Coats, A.J.S. ESC Scientific Document Group. 2016 ESC Guidelines for the diagnosis and treatment of acute and chronic heart failure: The Task Force for the diagnosis and treatment of acute and chronic heart failure of the European Society of Cardiology (ESC)Developed with the special contribution of the Heart Failure Association (HFA) of the ESC. Eur. Heart J. 2016, 37, 2129-2200. [PubMed]

10. Steinhaus, M.E.; Buller, L.T.; Romero, J.A.; Lee, Y.Y.; Figgie, M.P.; McLawhorn, A.S. Body Mass Index Classification Is Independently Associated with Health-Related Quality of Life after Primary Total Knee Arthroplasty: An Institutional Registry-Based Study. J. Knee Surg. 2020, 33, 399-409. [CrossRef]

11. Kroenke, K.; Spitzer, R.L.; Williams, J.B. The PHQ-9: Validity of a brief depression severity measure. J. Gen. Intern. Med. 2001, 16, 606-613. [CrossRef] [PubMed] 
12. Rozanski, A.; Blumenthal, J.A.; Kaplan, J. Impact of psychological factors on the pathogenesis of cardiovascular disease and implications for therapy. Circulation 1999, 99, 2192-2217. [CrossRef] [PubMed]

13. Carney, R.M.; Freedland, K.E. Depression and coronary heart disease. Nat. Rev. Cardiol. 2017, 14, 145-155. [CrossRef] [PubMed]

14. Rutledge, T.; Reis, V.A.; Linke, S.E.; Greenberg, B.H.; Mills, P.J. Depression in heart failure a meta-analytic review of prevalence, intervention effects, and associations with clinical outcomes. J. Am. Coll. Cardiol. 2006, 48, 1527-1537. [CrossRef]

15. Celano, C.M.; Villegas, A.C.; Albanese, A.M.; Gaggin, H.K.; Huffman, J.C. Depression and Anxiety in Heart Failure: A Review. Harv. Rev. Psychiatry 2018, 26, 175-184. [CrossRef]

16. Faris, R.; Purcell, H.; Henein, M.Y.; Coats, A.J. Clinical depression is common and significantly associated with reduced survival in patients with non-ischaemic heart failure. Eur. J. Heart Fail. 2002, 4, 541-551. [CrossRef]

17. Jiang, W.; Kuchibhatla, M.; Clary, G.L.; Cuffe, M.S.; Christopher, E.J.; Alexander, J.D.; Califf, R.M.; Krishnan, R.R.; O'Connor, C.M. Relationship between depressive symptoms and long-term mortality in patients with heart failure. Am. Heart J. 2007, 154, 102-108. [CrossRef] [PubMed]

18. Konstam, V.; Moser, D.K.; De Jong, M.J. Depression and anxiety in heart failure. J. Card Fail. 2005, 11, 455-463. [CrossRef]

19. Celik, E.; Cay, S.; Sensoy, B.; Murat, S.; Oksuz, F.; Cankurt, T.; Ali Mendi, M. Heart Failure Functional Class Associated with Depression Severity But Not Anxiety Severity. Acta Cardiol. Sin. 2016, 32, 55-61.

20. Nichols, G.A.; Moler, E.J. Cardiovascular disease, heart failure, chronic kidney disease and depression independently increase the risk of incident diabetes. Diabetologia 2011, 54, 523-526. [CrossRef]

21. Anderson, R.J.; Freedland, K.E.; Clouse, R.E.; Lustman, P.J. The prevalence of comorbid depression in adults with diabetes: A meta-analysis. Diabetes Care 2001, 24, 1069-1078. [CrossRef]

22. Heo, S.; Moser, D.K.; Pressler, S.J.; Dunbar, S.B.; Lee, K.S.; Kim, J.; Lennie, T.A. Association between obesity and heart failure symptoms in male and female patients. Clin. Obes. 2017, 7, 77-85. [CrossRef] [PubMed]

23. Batalli, A.; Ibrahimi, P.; Bytyçi, I.; Ahmeti, A.; Haliti, E.; Elezi, S.; Henein, M.Y.; Bajraktari, G. Different determinants of exercise capacity in HFpEF compared to HFrEF. Cardiovasc. Ultrasound 2017, 15, 12. [CrossRef] [PubMed] 